\title{
Design of a System of High Voltage Pulsed Power Converters for CERN's Linac4 $\mathrm{H}^{-}$Ion Source
}

\section{Aguglia}

CERN, Geneva, Switzerland

\section{Keywords: Linac4}

\begin{abstract}
This paper presents the complete design and experimental validations of the full scale prototype of a system of three new high voltage pulsed power converters for the CERN Linac4 $\mathrm{H}-$ source. The system requires three pulsed voltages $(50 \mathrm{kV}, 40 \mathrm{kV}$ and $25 \mathrm{kV}$ to ground) at $2 \mathrm{~Hz}$ repetition rate, for a $700 \mu$ s of usable flat-top. The solution presents switching frequency ripplefree voltages and a minimal stored energy to protect the ions source from arc events consequences. The main design aspects are presented. Experimental results on the final full-scale prototype are presented and show excellent behaviour in nominal and short circuit operations.
\end{abstract}

Presented at: IEEE pulsed power and plasma science conference (PPPS),

San Francisco, USA, June 2013

Geneva, Switzerland

November, 2014 


\title{
Design of a System of High Voltage Pulsed Power Converters for CERN's Linac4 $\mathrm{H}^{-}$Ion Source
}

\author{
Davide Aguglia, Member, IEEE \\ CERN - European Organization for Nuclear Research, Technology Dept., Electric Power Converter Group \\ CH-1211 Geneva 23, Switzerland \\ e-mail : davide.aguglia@cern.ch
}

\begin{abstract}
This paper presents the complete design and experimental validations of the full scale prototype of a system of three new high voltage pulsed power converters for the CERN Linac4 $H^{-}$source. The system requires three pulsed voltages $(50 \mathrm{kV}$, $40 \mathrm{kV}$ and $25 \mathrm{kV}$ to ground) at $2 \mathrm{~Hz}$ repetition rate, for a $700 \mu \mathrm{s}$ of usable flat-top. The solution presents switching frequency ripplefree voltages and a minimal stored energy to protect the ions source from arc events consequences. The main design aspects are presented. Experimental results on the final full-scale prototype are presented and show excellent behaviour in nominal and shortcircuit operations.
\end{abstract}

\section{NOMENCLATURE}

$e-d u m p \quad$ Electrons dump electrode

$I G B T_{\text {lin }} \quad$ Voltage regulating linear IGBT

$I G B T_{s w} \quad$ Main IGBT switch

$C_{D} \quad$ Pulse transformer damping capacitor $\quad F$

$C_{\text {main }}$ Converter main capacitor bank

$C_{U S N}$

$L_{m}$

$R_{D}$

$R_{\text {dis }}$

$R_{\text {preld }}$

$R_{s}$

$R_{U S N}$ events. Two main issues of supplying the $H^{-}$source with DC voltages can be identified :

1) High probability of arc events due to DC electric fields.

2) Electrode damage due to energetic arc events because of high stored energy into the necessary voltage stabilizer capacitor back.

The solution consists in developing dedicated pulsed power converters which are decreasing the arc events probability, by supplying the HV only when needed, and presenting a very low energy storage.

\section{III. $H^{-}$SOURCE DESCRIPTION AND VOLTAGES SPECIFICATIONS}

An introduction and a review on $H^{-}$sources for particles accelerators can be found in [3]. Figure 1 presents a simplified cross-sectional view of the $H^{-}$source under consideration. Molecular Hydrogen $\left(H_{2}\right)$ is injected into a ceramic chamber (plasma chamber), where it is heated-up by Radio Frequency (RF) power, thanks to a $2 \mathrm{MHz}$-fed coil. $\mathrm{H}^{-}$ions are then extracted from the plasma chamber thanks to intense electric fields produced by voltage potentials applied on the puller electrode.

This paper presents all the design and experimental validation of such a system, which includes three synchronized pulsed voltages of $50 \mathrm{kV}, 25 \mathrm{kV}$, and $40 \mathrm{kV}$ to ground.

\section{INTRODUCTION}

The new linear accelerator (Linac4) under construction at CERN [1] is designed to provide a $160 \mathrm{MeV}$ negative hydrogen ions $\left(H^{-}\right)$beam to the Proton Synchrotron Booster (PSB). Linac4 is intended to replace the ageing $50 \mathrm{MeV}$ Linac2 and aims to increase the $L H C$ beam luminosity. Several $H^{-}$sources are under development [2] in view of gradually increasing the $H^{-}$beam intensity to $80 \mathrm{~mA}$ with a limited co-extracted electron beam of $1 A-1.5 A$. Previous attempts to reach this $H^{-}$beam intensity showed the necessity of replacing the source's High Voltage (HV) DC power supplies with high voltage pulsed power converters. Originally the system was composed of commercial HV power supplies feeding the source through capacitor banks, with the objective of stabilizing the voltage during the perturbing extracted beam's image current. However, such stored energy in the capacitors banks were damaging the source electrodes during internal arc

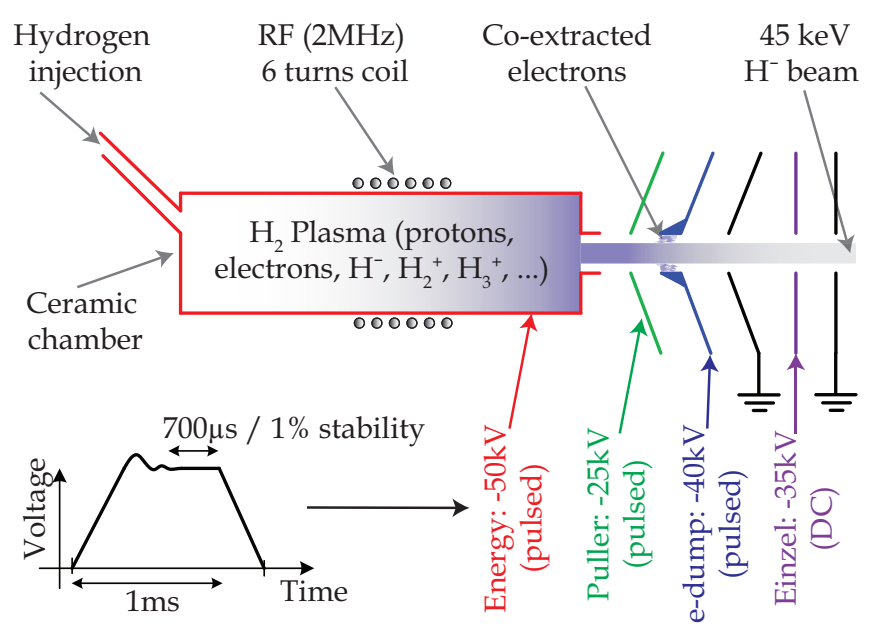

Fig. 1. $H^{-}$source simplified configuration cross-sectional view. 
The objective of the source is to extract a $45 \mathrm{keV} \mathrm{H}^{-}$beam. In order to consider a margin the Energy power converter (Fig. 1) is designed to deliver $50 \mathrm{kV}$. The energy of the beam is imposed by the potential difference between the plasma chamber and the grounded electrodes in Fig. 1. A puller electrode with a potential of $-25 \mathrm{kV}$ is used to extract the $\mathrm{H}^{-}$ ions from the plasma chamber. The generated plasma consists of protons, electrons, $\mathrm{H}^{-}, \mathrm{H}_{2}^{+}$and $\mathrm{H}_{3}^{+}$. The issue with negative ion sources lies in the fact that during the extraction process electrons are co-extracted as well. The necessity of cleaning the beam from electrons imposes the insertion of a supplementary electrode whose purpose is to dump the coextracted electrons. This electrode is the so-called $e-d u m p$ in Fig. 1. Due to their lower mass compared to $\mathrm{H}^{-}$ions, the electrons are deflected toward this electrodes $(e-d u m p)$, via a weak magnetic field produced by a dipole magnet, whereas the ions continues to the exit of the source. Furthermore a socalled Einzel Lens electrode is supplied in DC, its purpose being to focus the beam before exiting the source.

The nominal $\mathrm{H}^{-}$beam intensity is $80 \mathrm{~mA}$ and the extraction period is $700 \mu \mathrm{s}$ with a repetition rate of $2 \mathrm{~Hz}$. Therefore the pulsed power converters have to provide pulses with a minimum flat-top length of $700 \mu \mathrm{s}$. The flat-top stability specification has been set to $1 \%$ and voltages rise and fall times are not critical, however, in view of minimizing the arc events probability, one has to try minimising them. In term of currents, the specifications varies depending on the electrode. Similarly to capacitive pick-ups, in each electrode, as well as in the plasma chamber, a beam image current is produced when a $H^{-}$bunch is extracted (Fig. 2). The analytical evaluation of the precise image current value in each electrode can be tedious, and depends on many variables [4] (such as electrodes shape and dimensions, longitudinal bunch distribution, bunch velocity, external impedance $Z$, ecc.).

A first estimation of image currents led to a maximal peak value of $200 \mathrm{~mA}$. The $e-d u m p$ electrode current is composed of the estimated co-extracted electronic current and the image current. The nominal current flowing in the $e-d u m p$ electrode is then $1.7 \mathrm{~A}$. Table I summarizes the specifications. Notice that voltages are positively and negatively defined. For commissioning purposes, and in case an early upgrade from Linac2 to Linac4, the source shall be able to produce protons
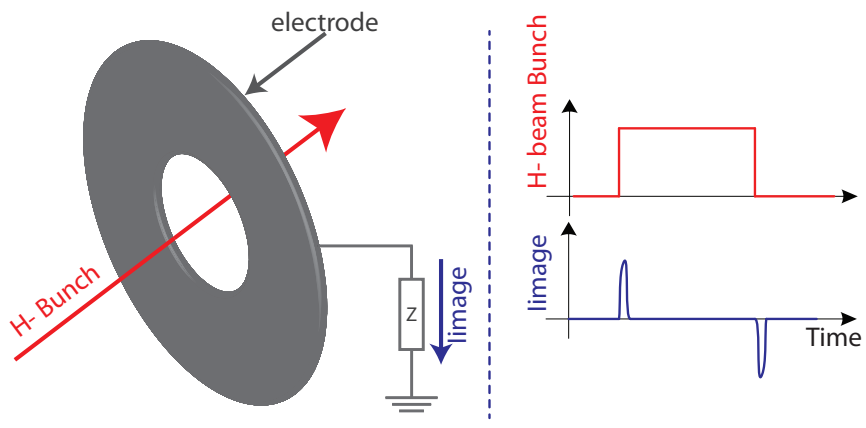

Fig. 2. Image current phenomena principle.
TABLE I

$H^{-}$SOURCE PULSED POWER CONVERTERS SPECIFICATIONS.

\begin{tabular}{lrll}
\hline \hline \multicolumn{4}{c}{ Common specifications } \\
\hline Flat-top length & $t_{f l a t}$ & 700 & $\mu s$ \\
Pulse rise/fall times & $t_{r f}$ & $<300$ & $\mu s$ \\
Flat-top stability & $S_{f t}$ & $<1$ & $\%$ \\
Pulse repetition rate & $R e p_{r}$ & 2 & $H z$ \\
Under-shoot voltage & $V_{U S}$ & 0 & $V$ \\
\multicolumn{4}{c}{ Energy/Plasma chamber } \\
\hline Nominal voltage (to ground) & $V_{e g}$ & \pm 50 & $k V$ \\
Nominal pulse current & $I_{e}$ & 0.2 & $A$ \\
\multicolumn{4}{c}{ Puller/extraction electrode } \\
\hline Nominal voltage (to ground) & $V_{p g}$ & \pm 25 & $k V$ \\
Nominal voltage (to energy) & $V_{p e}$ & \pm 25 & $k V$ \\
Nominal pulse current & $I_{p}$ & 0.2 & $A$ \\
\multicolumn{4}{c}{ Electron dump electrode } \\
\hline Nominal voltage (to ground) & $V_{d g}$ & \pm 40 & $k V$ \\
Nominal voltage (to energy) & $V_{d e}$ & \pm 10 & $k V$ \\
Nominal pulse current & $I_{d}$ & 1.7 & $A$ \\
\hline \hline
\end{tabular}

as well as $H^{-}$beams. It is not required that the voltage reversal is automatic, however a few hours only are allocated for changing configuration ( $H^{-}$to protons or vice-versa).

Figure 3 presents the pulsed voltages main specifications.

\section{POWER CONVERTERS DESIGN}

\section{A. Energetic problematic and special high voltage connection}

There are several topological solutions for the required power converters, however at these voltage levels and requested dynamics, four-quadrants converters start to be a very complex choice. One-quadrant converters topologies are the most used for these purposes, and an overview is given in Section IVC. By considering a connection of all power converters to

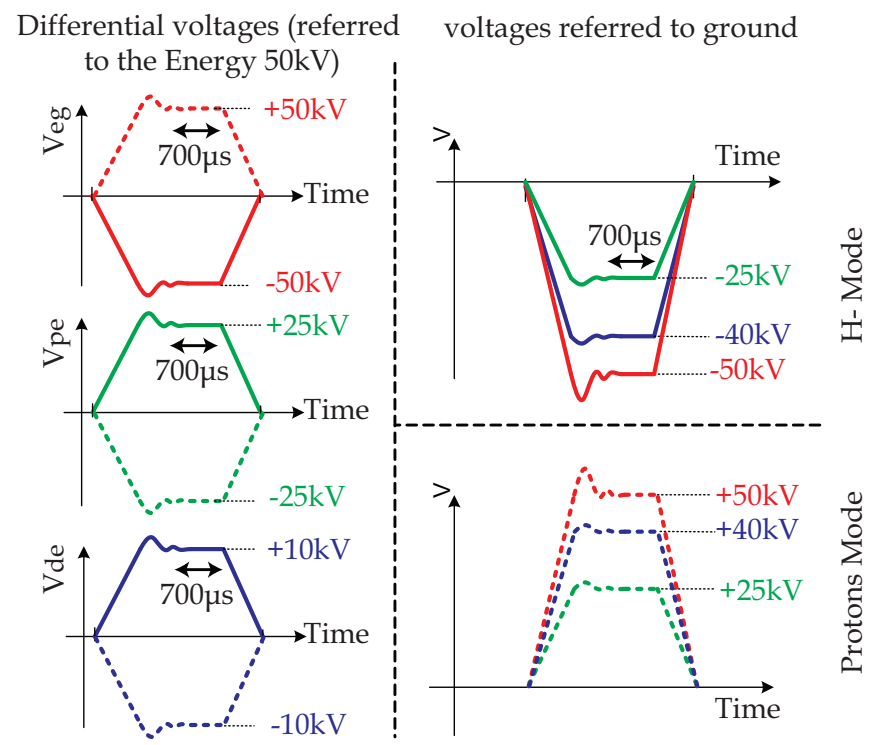

Fig. 3. Pulsed voltages vs. time definition. 
ground as the example for the electron-dump depicted in Fig. 4 a), one can notice an issue arising if a one-quadrant converter is considered. Indeed, with this connection the power converter shall produce a negative voltage with respect to ground, and the electrons caught from the beam are flowing toward the power converter negative potential. The electric current is positively defined as the direction of positive charges movement, therefore in opposite direction of the electrons movement. Considering these conventions one notices that in the configuration of Fig. 4 a) the energy is oriented toward the power converter. With a one-quadrant converter this is a problem, since its capabilities allow to increase the voltage (negatively) only, and a voltage decrease cannot be controlled (can be done passively by pre-loading the system with a resistor though). For instance, suppose that the electron dump power converter is operating at its nominal voltage value of $-40 \mathrm{kV}$ to ground. Then electrons are caught from the $e-d u m p$ electrode and they tend to negatively increase the voltage below $-40 \mathrm{kV}$. The one-quadrant converter can not decrease the voltage to reach the nominal value of $-40 \mathrm{kV}$.

The only solution for using a one-quadrant converter consists in referencing the electron dump power converter to the Energy one $(-50 k \mathrm{~V})$ as illustrated in Fig. $4 \mathrm{~b})$. In this case, when electrons are caught from the $e-d u m p$ electrode, the power converter voltage tend to decrease, making the correction possible. Notice that in this configuration the electron dump power converter must deliver $-10 k \mathrm{~V}$ only, compared to the $-40 k V$ of the solution of Fig. 4 a). This voltage decrease

a)

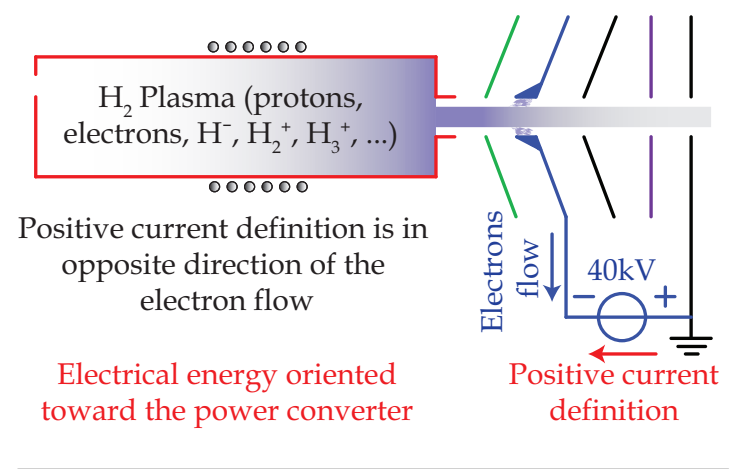

b)

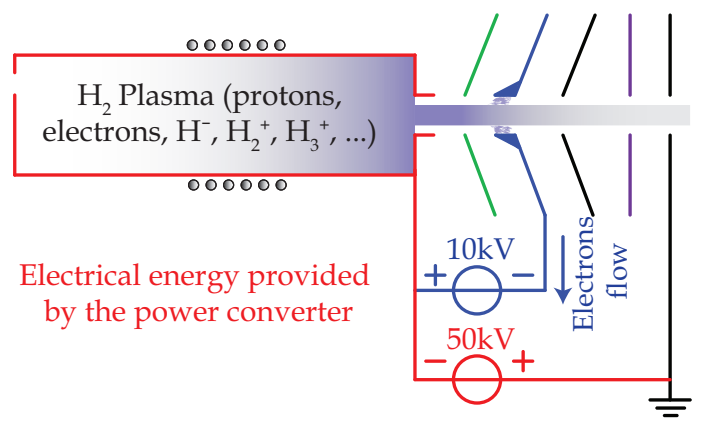

Fig. 4. Energetic issues vs. connection of HV 1-quadrant power converters. divides the nominal power by a factor four, since the current requirement remains unchanged.

In principle the puller $(-25 k \mathrm{~V})$ power converter could be referenced to ground, since no electrons are caught from the corresponding electrode. However, this is only an ideal case. By experience one knows that some electrons can be caught by the puller electrode too, leading to the same issue as for the electron dump power converter. It is therefore necessary to reference the puller power converter to the Energy $(-50 \mathrm{kV})$ one as well. Finally, using one-quadrants converters leads to an increase in the complexity of the power converters interconnections.

\section{B. Mechanical integration and general converters topology}

Mechanical integration issues are greatly affecting the general power converters system topology. Indeed, HV pulsed power systems have the general peculiarity of needing the load to be physically close to the power converter, due to the HV cable stray capacitance increasing with their length and the associated loss of dynamics (rise and fall times). As shown in Fig. 5 the $H^{-}$source is placed inside a Faraday cage in the beam-line tunnel. A solution may consist in placing the whole power converters system inside the Faraday cage, however, due to access times in case of failure, this configuration is not suitable. The access time into this region of the accelerator is also increased since special access controls are necessary due to radiation. Notice that Linac4 will produce the beam for all the accelerators complex at CERN, and a very high beam availability is required. The cable distance between the dedicated power converters rack on the first floor and the Faraday cage is $50 \mathrm{~m}$.

The solution naturally converges toward a topology where the converters power electronics systems are placed on the $1^{\text {st }}$ floor, and a step-up voltage system ensured by pulse transformers is integrated inside the Faraday cage, as presented in Fig. 5.

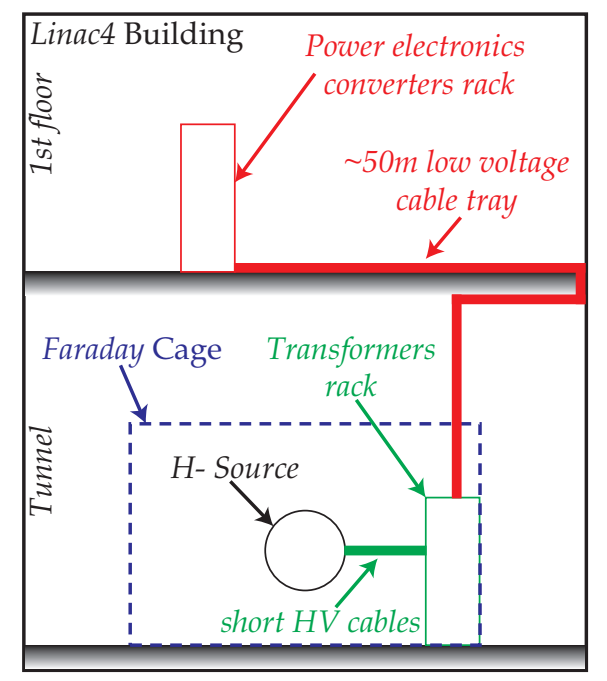

Fig. 5. Simplified cross-sectional view of the Linac4 building and power converters integration. 
This configuration presents the advantage of having long cables on the low voltage side, which do not catastrophically affect the system dynamics, and passive components only in the tunnel.

\section{Power converter topology selection}

Fully solid-state converters topologies such as Marx-type bi-polar generators [5], resonant step-up converters or other hybrid/alternative solutions [6] [7] [8] [9] [10] are interesting solutions for this application. However, as mentioned in the last section, the global topology of the system is mainly imposed by the mechanical integration requirements. In particular the topology shall present a low voltage section for the medium distance power transmission, and a final voltage step-up stage.

For the sake of reducing the number of components and the complexity, and due to the quite relaxed requirements on rise and fall times, the most simple topology using a monolithic HV pulse transformer has been retained. The general configuration of the system is presented in Fig. 6 . The solution includes three identical, low voltage, power converters, and three different HV pulse transformers. The three power converters are strongly coupled by the secondary pulse transformer special connection. Notice that the puller and the $e-d u m p$ pulse transformers (TR2 and TR3) are referenced to the Energy pulse transformer (TR1). The primary winding of each transformer is referred to ground and is rated at $700 \mathrm{~V}$, simplifying the design of the three power converters. Due to restricted space inside the Faraday cage, all three transformers must fit in one standard 19" rack.

Several topologies can be considered for the power converter. Figure 7 shows two typical converter basic topologies which can be employed. On Fig. 7 a) a typical switch-mode buck topology is shown whereas in Fig. 7 b) a classical power modulator, often used as a klystron modulator, is presented. The latter topology is typically used when the primary voltage

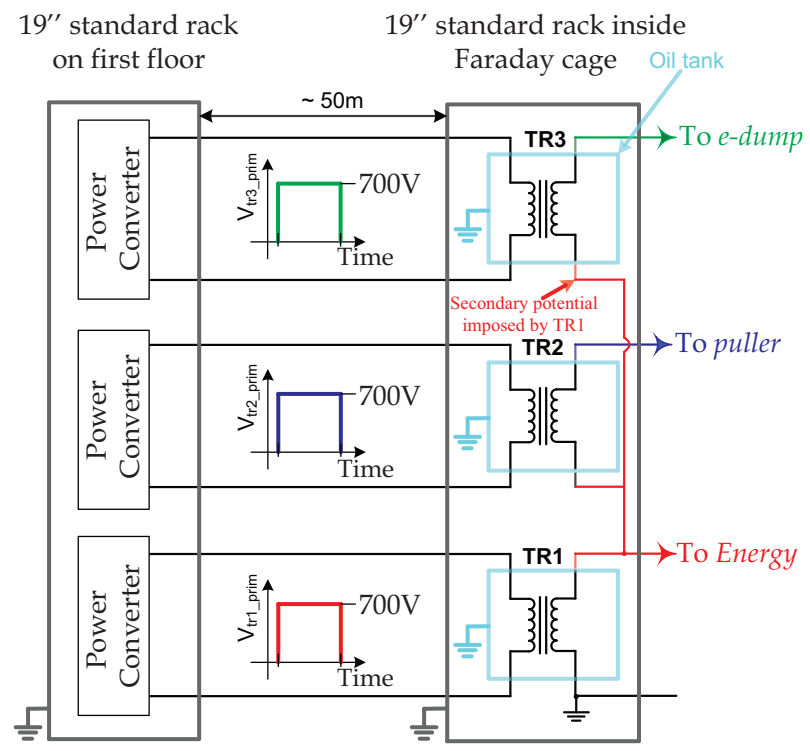

Fig. 6. General converters system configuration.
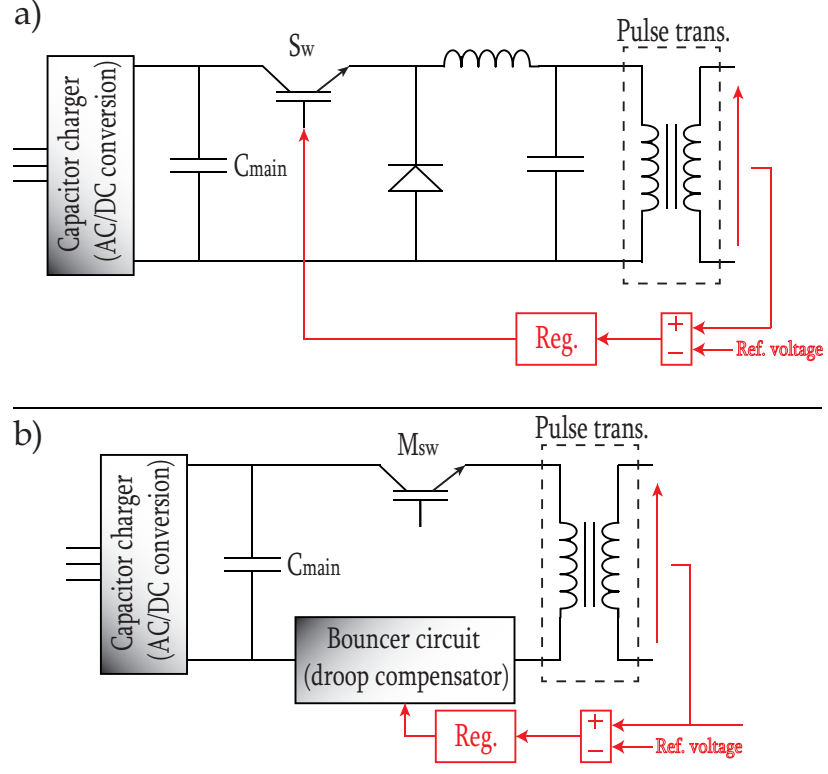

Fig. 7. Possible power electronics topologies.

is higher than $1 \mathrm{kV}$ and where a considerable amount of energy must be taken from the main capacitor bank $C_{\text {main }}$.

For this application the problematic lies in the unknown behaviour of the ions source with respect to switching harmonics. Indeed the initial specification of $0.1 \%$ of maximal voltage ripple during the pulses, is very challenging if the necessary voltage bandwidth (voltage rise-time) is considered. Considering the topology of Fig. 7 a), the $L C$ filter should be designed such that an attenuation of $60 \mathrm{~dB}$ (ripple specifications) is achieved at the switching frequency. Supposing a switching frequency of $f_{s w}=20 \mathrm{kHz}$ with an IGBT technology of $1.7 \mathrm{kV}$, a second order filter presenting $-60 \mathrm{~dB}$ at $20 \mathrm{kHz}$ would have a cutting frequency at $\sim 750 \mathrm{~Hz}$, which is not enough to guarantee a rise-time better than $t_{r f}<300 \mu s$.

Solutions such as multiphase interleaved topologies [11] or special active filtering methods [12] could be used to extend the bandwidth at low voltage ripples. However, due to the needs in reliability, the choice consisted in selecting a topology similar to the one of Fig. 7 b), combined with a linear driven IGBT-based bouncer circuit, in order to get rid of the ripple issue while keeping a high voltage bandwidth.

The final retained topology is presented in Fig. 8. It mainly consists of a main switch $S_{s w}$, permanently closed during the pulse, the step-up pulse transformer, and an IGBT $\left(I G B T_{L i n}\right)$ working as controllable resistor to regulate the output pulsed voltage. The utilization of IGBTs in their active region is a proven technique employed in high performances pulsed current converters [13]. At the end of one pulse, $S_{w}$ is opened and diode $D_{H V}$ opens in order to force the demagnetizing current of the transformer to flow into the $D_{U S N}, R_{U S N}$, and $C_{U S N}$ network, and to preserve the $H^{-}$source from negative voltages. A discharging resistor $R_{d i s}$ is placed at the output of the circuit in order to discharge the capacitive load (ions source) between two pulses. A series resistor $R_{s}$ is also placed 


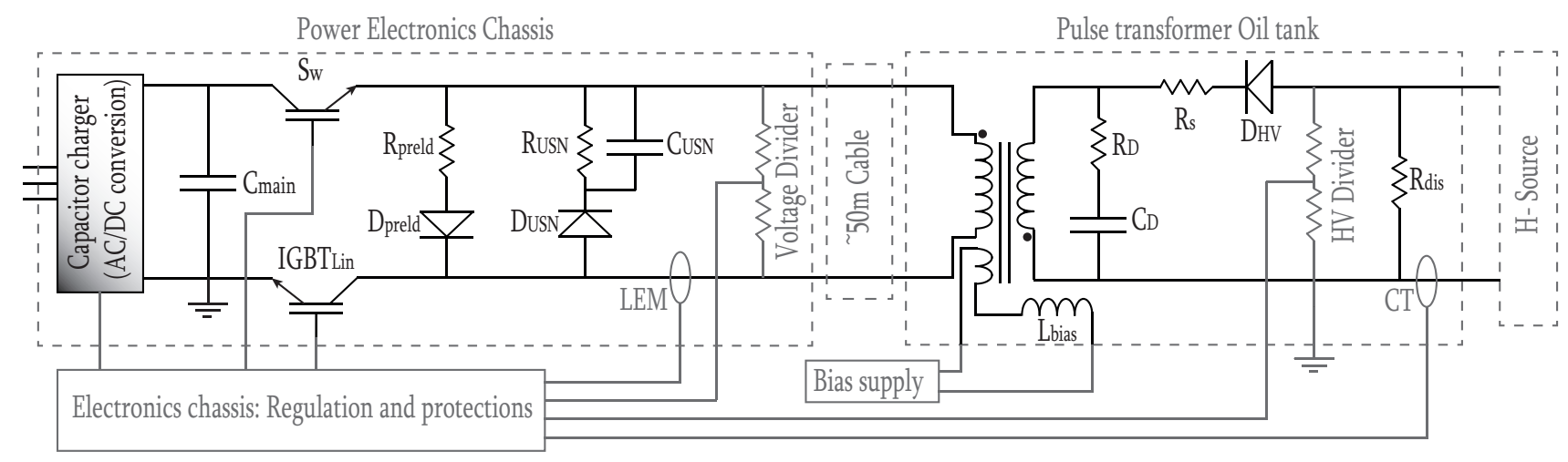

Fig. 8. Final Topology of one pulsed HV system for the $H^{-}$ions source.

in the oil tank to protect the power converter and the load from high currents due to arc events inside the source. While no image current of the beam is circulating in the secondary winding of the transformer (beginning of the pulse), the power converter is not loaded, and the pulse transformer can present high oscillating voltage. To damp the transformer voltage, an $R C$ series network is placed at its output. The current in the load is very low while there is no ion beam and thus the regulating IGBT $\left(I G B T_{L i n}\right)$ can not be properly operated in its active region. For this purpose a pre-loading resistor $R_{\text {preld }}$ (with a series diode $D_{\text {preld }}$ ) has been foreseen. To reverse the voltage operation the system requires the reversal of the transformer primary winding connection as well as the diode $D_{H V}$.

\section{Design considerations for arc protection}

One of the main purposes of the proposed system is to mitigate arc events as well as their damaging effects inside the ions source. The calculation of the series resistance value $R_{s}$ derives from a trade-off which considers the minimization of the maximal arc energy inside the source as well as the power converter voltage regulation capabilities to correct the voltage droop across $R_{s}$ when the beam image current flows into it. The theoretical worst arc condition occurs when the arc resistive impedance equals the protection series resistance $R_{s}$. When an arc is detected the system reacts by turning off $S_{s w}$ in roughly $5 \mu \mathrm{s}$. At nominal operating conditions the maximal arc energy (to ground) for the $50 \mathrm{kV}$ power converter is $375 \mathrm{~mJ}$, $234 \mathrm{~mJ}$ for the $25 \mathrm{kV}$ and $6 \mathrm{~J}$ for the $10 \mathrm{kV}$ one. Arc energy mitigation for the $10 \mathrm{kV}$ power converter is limited due to the fact that the series resistance must be low enough to reduce the voltage perturbation created by the electrons flow of $1.7 \mathrm{~A}$.

Figure 9a) illustrates the adopted experimental methodology to test the rapid reaction to a ground short-circuit on each power converter. A spark gap was used to create an arc event on several locations of the pulse flat-top. The spark-gap has a triggering circuit allowing a fine tuning of the arc event time. Fig $9 \mathrm{c}$ ) shows the result of one short-circuit test on the $50 \mathrm{kV}$ power converter.

\section{EXPERIMENTAL VALIDATION ON FULL SCALE PROTOTYPE}

A first full-scale prototype has been constructed and operated at the $\mathrm{H}^{-}$test stand (called the $3 \mathrm{MeV}$ test stand), whose purpose is to test the first section of the Linac4 accelerator (a few meters). Figure 10 a) shows the system under test in a laboratory. The left rack contains the three electronics chassis and the three power electronics chassis, and the right rack contains the three HV pulse transformers (mounted as drawers for fast interventions). Figure $10 \mathrm{~b}$ ) shows the transformers rack installed at the $3 \mathrm{MeV}$ test stand (just beside the Faraday Cage). First tests were performed on a dummy load consisting of a spark-gap in series with a resistor to create the load current during the pulse as depicted in Fig. 9b). Figure 11 shows two views of the extractable top cover of a transformer tank, which holds all HV components illustrated in Fig. 8. The drawer transformers and the top cover mechanical system has been developed for fast intervention in the Linac4 tunnel in case of failure. First results of the prototype system under nominal operation are depicted in Fig. 12. Notice how the electrondump current is not only perturbing the $e-d u m p$ voltage,
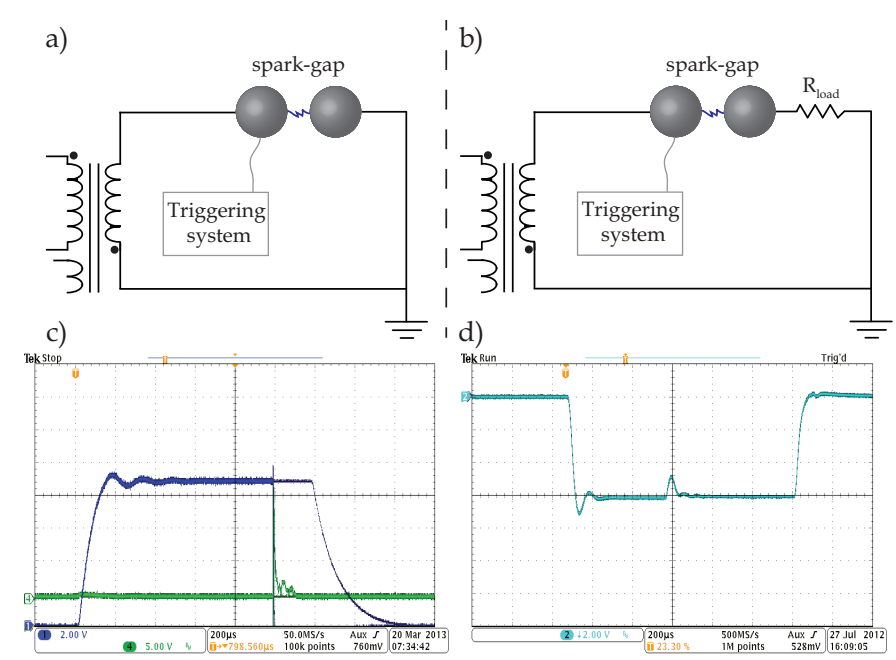

Fig. 9. spark-gap utilization for short-circuit and full load tests. 
a)

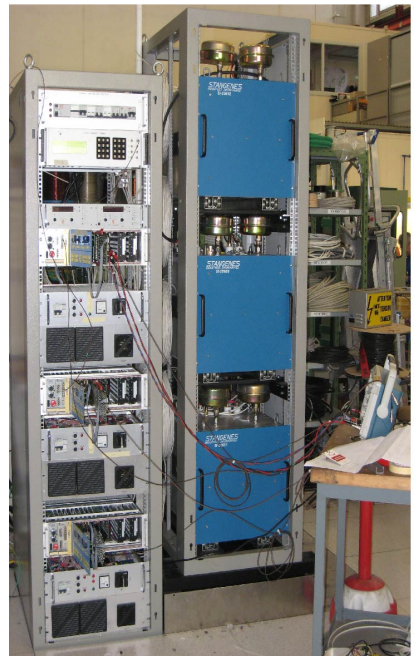

b)

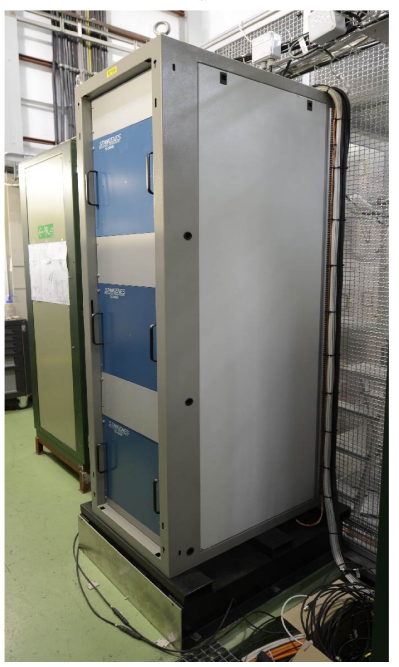

Fig. 10. Prototype system : a) under test; b) in operation at the test stand.

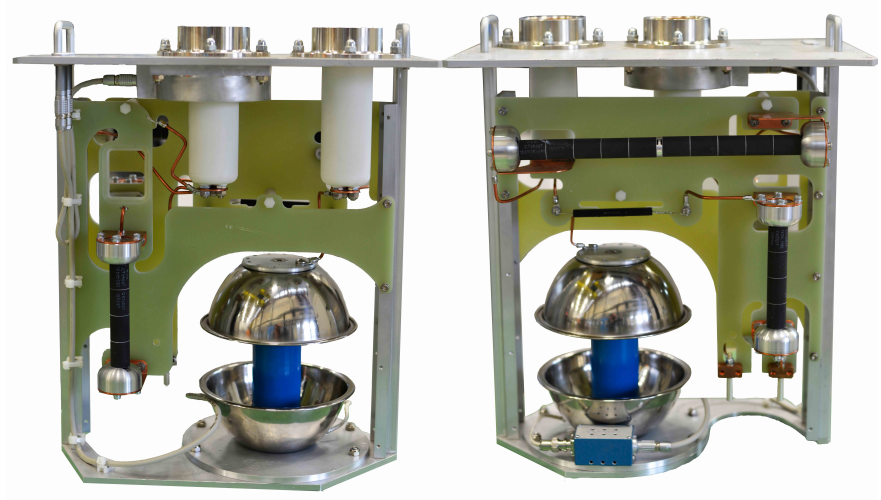

Fig. 11. Front and rear views of the extractable transformer top cover holding all $\mathrm{HV}$ components (resistors, HV divide, current transformer and HV connectors).

but the other voltages as well. These results were measured with a preliminary analog electronics voltage regulation. A new dedicated digital electronics system is under development to better reject the perturbation on the voltage flat-tops via generalized polynomial $R S T$ controllers.

\section{CONCLUSION}

A new system of pulsed power converters for the $H^{-}$ ion source of Linac4 has been designed and experimentally validated. The topology is based on a series of three HV pulse transformers with their secondary windings interconnected. Further work is focusing on the controller optimization via a digital control electronic. Since February 2013 the new ion source is successfully operating, and in particular the issue of damaging arc events previously observed has now been resolved by the use of pulsed powering.
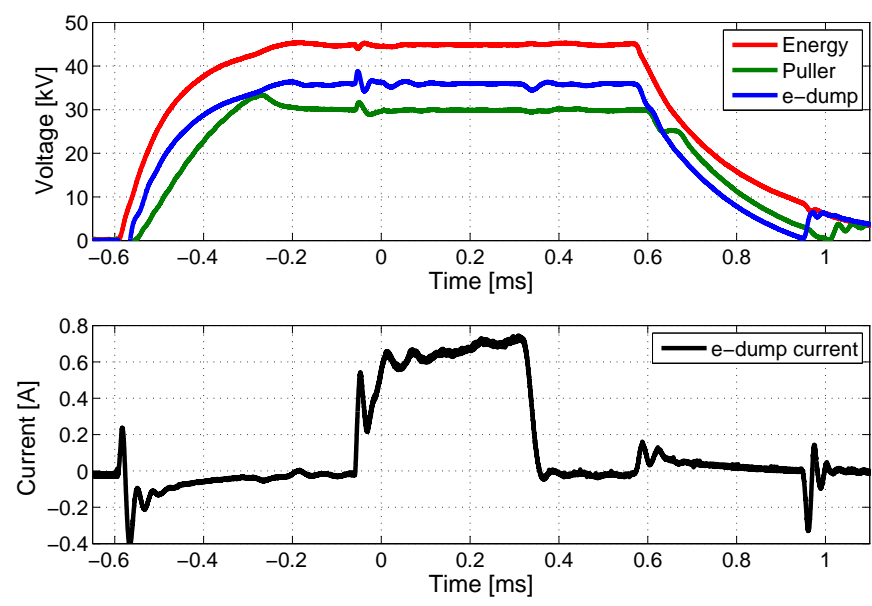

Fig. 12. Measured voltages on the prototype and electron-dump current.

\section{REFERENCES}

[1] M. Vretenar et al. The linac 4 project at CERN, $2^{\text {nd }}$ International Particle Accelerator Conference, San Sebastian, Spain, 4 - 9 Sep 2011, pp. TUOAA03.

[2] J. Lettry et al. $H$ - Ion sources for CERN's Linac4, in American Institute of Physics Proceedings (AIP), NIBS 2012, pp. 1 - 11.

[3] D. P., Moehs, J. Peters, J. Sherman, Negative hydrogen ion sources for accelerators, IEEE Trans. Plasma Sci., vol.33, no.6, pp. 1786-1798, Dec. 2005

[4] P. Forck, P. Kowina, D. Liakin, Beam Position Monitors, CERN Accelerator School, course on "Beam Diagnostics", France, 28 May - 6 June 2008, pp. $1-42$.

[5] H. Canacsinh, L. M. Redondo, J. F. Silva, Marx-Type Solid-State Bipolar Modulator Topologies : Performance Comparison, IEEE Tran. Plasma Sci., vol.40, no.10, pp.2603-2610, Oct. 2012.

[6] J. O. Rossi, E. Schamiloglu, M. Ueda, Advances in High-Voltage Modulators for Applications in Pulsed Power and Plasma-Based Ion Implantation, IEEE Trans. Plasma Sci., vol.39, no.11, pp.3033-3044, Nov. 2011.

[7] W. A. Reass, D. M. Baca, R. F. Gribble, D. E. Anderson, J. S. Przybyla, R. Richardson, J. C. Clare, M. J. Bland, P. W. Wheeler, High-Frequency Multimegawatt Polyphase Resonant Power Conditioning, IEEE Trans. Plasma Sci., vol.33, no.4, pp.1210-1219, Aug. 2005.

[8] P. Davari, F. Zare, A. Ghosh, H. Akiyama, High-Voltage Modular Power Supply Using Parallel and Series Configurations of Flyback Converter for Pulsed Power Applications, IEEE Trans. Plasma Sci., vol.40, no.10, pp.2578-2587, Oct. 2012.

[9] A. Pokryvailo, C. Carp, C. Scapellati, A High-Power High-Voltage Power Supply for Long-Pulse Applications, IEEE Trans. Plasma Sci., vol.38, no.10, pp.2604-2610, Oct. 2010.

[10] L. M. Redondo, J. F. Silva, Flyback Versus Forward Switching Power Supply Topologies For Unipolar Pulsed-Power Applications, IEEE Trans. Plasma Sci., vol.37, no.1, pp.171-178, Jan. 2009.

[11] D. Aguglia, $2 M W$ active bouncer converter design for long pulse klystron modulators, in Proc. $14^{t h}$ Power Electronics and Applications Conference (EPE 2011), pp.1-10, Sept. 12011.

[12] F. C. Magallanes, D. Aguglia, C. de Almeida Martins, P. Viarouge, Active damping filter for high bandwidth - Low ripple pulsed converters, in proc. $15^{\text {th }}$ International Power Electronics and Motion Control Conference (EPE/PEMC), pp.DS2b.15-1,DS2b.15-7, 4-6 Sept. 2012.

[13] J.-M. Cravero, F. C. Magallanes, Control of high power IGBT modules in the active region for fast pulsed power converters, accepted for the $15^{\text {th }}$ Power Electronics and Applications Conference (EPE), 3-5 Sept. 2013. 